\title{
The Design-driven Material Innovation Methodology
}

\author{
Ferrara, Marinella ${ }^{a} \&$ Lecce, Chiara ${ }^{b}$ \\ ${ }^{a}$ Assiciate professore of Industrial Design- Politecnico di Milano, Italy, marinella.ferrara@polimi.it \\ ${ }^{\mathrm{b}} \mathrm{PhD}$ - Politecnico di Milano, Italy, chiara.lecce@polimi.it
}

\begin{abstract}
A new materials research scenario emerges from design field, where scientists, enterprises, inventors, creative communities, and material industries are becoming deeply engaged in the creative challenge to achieve material functionality and meanings ideas for disruptive innovation. Considering and integrating design methods, technological approaches and studies on innovation, the Material Design Culture Research Center (MADEC) of Politecnico di Milano developed in the last years a specific methodology able to manage the whole design process from tailor-made material to product systems, integrating different actors of innovation, enhancing capabilities of open explorations, and reducing the time-to-market for materials and products. This paper presents the DdMIM (Designdriven Material Innovation Methodology) as a systematic approach and strategic tool for research centers, design schools, practitioners and SMEs. A specific material could be a starting point of the process, but not only. What the method really tries to do is to let understand how to use technologies (and advanced materials) contextualizing them within a wider socio-cultural and economic scenario. After a brief forward of the method theoretical premises, this paper will analyzes the seven steps suggested by the methodology: Data collection, Sensing, Sensemaking, Envisioning, Specifying, Setting up, Placing. These phases are associated with a selection of case studies to help its comprehension. Actually the DdMIM is part of the "Design for Enterprises" the European training program for SMEs, started this year and operating for the next two years in order to help SMEs to enhance the capabilities for Design-Driven. In the "Design for Enterprises" training program the DdMIM is part of the module "Design for Materials", and help enterprises to manage a design process for product and services innovation where different actors like materials scientists, suppliers, creative communities and consumers are getting engaged.
\end{abstract}

Keywords: Design Research, Material Design, Material-product development processes, human-centred design, design methodology. 


\section{Premise: the contemporary material design scenario}

At the beginning of the new millennium, some authors theorized the dematerialization of products as an effect of the miniaturization and a new eco-friendly design agenda.

A guilt-feelings pushed design research community focusing towards immaterial production, and raising of environment awareness.

After many developments on intangibility, today we face a new idea of technology, based on increased environmental awareness and on greater control on productive processes, enables design push forward its horizons.

Design research strongly came back to materials topic dealing with the new materials reality in a globalized and fast changing world, in order to engender disruptive innovation.

Over the past several decades, scientists, chemical engineers and physicists in many part of the world, have been busy tailor-making new advanced materials, built one atom at a time, one layer at a time, leading to a great variety of new material and production methods. Today, Advanced Materials have a very large economic size and they are essential for industrial and business development. Advanced materials are ads functionalities to materials in order to increase the added value of the products. They are very important for the development and innovation system ${ }^{36}$.

Advanced materials ads functionalities to materials in order to increase the added value of the products. This will enhance the competitiveness and also make it more difficult to copy a product.

Nevertheless the enormous effort of technological basic research for new materials only a small part of this work earns real applicative and market success. Very few materials succeed in being a determinant stimulus for products and systems innovation. Most material innovations fail ${ }^{37}$. While ideas abound, industrial research is less effective. While innovation is critical the usual process of managing innovation doesn't seems to work anymore.

In order to manage and expedite the conversion of technological innovation into marketable products ${ }^{38}$ and to adjust development processes to meet customer demands, the research need the design knowledge and skills.

Within certain production contexts and sectors material design is yet very appreciated.

Design is able to identify the more suitable applications of new materials, developing their functionalities according to technical proprieties and to the possibilities owned by the material to be easily molded and manipulated in order to achieve sensorial characteristics. Design allows attributing a specific identity to new materials, as the case of several plastic materials that could not be recognizable from their counterparts without a color design or a specific superficial texture.

In a world were the number of products becomes greater and greater, material can make the difference to the competitors, for the product distinctiveness in the market. The material should be pleasant and easily understood by consumers thanks to its sensorial characteristics, to its symbolic elements and thorough the message transmitted by the visual communication design, which is able to clarify the innovation value.

\footnotetext{
${ }^{36}$ The European Competitiveness Report 2010 has highlighted of KET (Key Enabling Technologies). Among KETs, Advanced Materials have a very large economic size and they are essential for further development of many other KETs.

${ }^{37}$ Smithers Rapra, an independent authority on rubber, plastics, and composite materials, report that around $80 \%$ of plastic products fail prematurely, $45 \%$ of these failures are due to poor material selection and characterization, $20 \%$ to unsatisfactory design and $15 \%$ to mis-use.

38 Actually take up times for the adoption of a new material, considering its technical development and its firs commercial application and diffusion, are very long: almost 20 years.
} 
Therefore what in the engineers' language is a question of physical parameters and technical proprieties has to be translated in terms of users' experience, perception and emotion. Only in this way consumers will accept the new material.

Today the appreciation acquired by design among the enterprises world goes beyond the consolidated modalities. Both in the field of scientific research and in business research, design skills are increasing their significant role, because they "close the cycle of innovation".

Scientists and engineers are problem solver as the designers can be, but to engender innovations of success requires not only technological exploitations but also a broader understanding of materials meaningful application for costumers, consumers and users. It is important to understand the trend of innovation driven by social, cultural, economic and environmental drivers and operate with a users and human-centred human approach.

Since design is capable of improving communication between different actors, it promotes mechanisms of innovation, lowering the risk that, after substantial funding, and scientific research being not adequately exploited. When new materials, products and production processes are conceived together, the industrial take-up time as well as time to market is minimized.

Therefore, design experts are approaching to a new collaborative research scenario where scientists, technology experts, humanists, material developers, suppliers, manufactures, product industries, distributors, societal stakeholders and final users are becoming deeply engaged in the creative challenge to achieve material functionality and meanings, playing a role in results of quality of life, productivity, economic progress, and sustainability.

Design faces many challenges regarding the collaboration between creative and production communities (Adamovic, 2014) ${ }^{39}$ :

- Different understanding in the limitations and complexity of the technology and timing;

- Gap between technology maturity and the short term expectations of creative partners;

- Small flexibility of the technology to adapt to the designer and end-user requirement;

Examples of recently launched projects seeking the collaboration between designers and scientists in the context of materials research are: "Light.Touch.Matters" a design driven development of touch sensitive luminous flexible plastics for applications in care \& well-being coordinated by Erik Tempelman of the TUDelft (Netherlands) form 2013; "Solar Design" for On-the-fly alterable thin-film solar modules for design driven applications coordinated by Nadja Adamovic form 2013 and "INNOMATNET" a networking of materials laboratories and innovation actors in various industrial sectors for product or process innovation.

Replaying to these challenges, it is necessary to define a new framework, even a method, by that the design research could work with the different actors of innovation, managing open explorations. Designers cannot know everything but they can open their minds and develop a more conscious understanding of this new field of design practice starting from a cultural point of view (Ferrara \& Lecce, 2015).

\footnotetext{
${ }^{39}$ Nadja Adamovic, Vienna University of Technology, Austria
} 


\section{MADEC: the Material Design Culture Research Center}

At the end of 2013, a team ${ }^{40}$ of researchers of Design Department of Politecnico di Milano proposed a research project for the creation of a Research Center to deal with the topic of the relationship between design and innovative material in the era of open innovation: the "Research Centre of Material Design Culture". (Lecce, 2015).

The research project combined different approaches starting from an historical, theoretical and cultural point of view reaching a more technical and advanced scenario related to the materials design research. The MADEC' funding research underlined the historical identity of Italian Design approach to materials (Bosoni \& Ferrara, 2014), and its possible evolution along the contemporary research trajectories of technological innovation scenarios with developing new approaches and methodologies (Ferrara \& Lecce, 2015).

MADEC has stressed on the issue that today the relationship between material and innovation is increasingly correlated to the creation of values and design competences, also depending to crossdisciplinary processes in which different skills are integrated. In these processes the implementation of Co-design and Open Design practices is fundamental.

Therefore, the Open Innovation paradigm presented by H. W. Chesbrough (2006) has been a critical starting point for our research model because it was presented as the antithesis of the traditional vertical integration model where internal research and development (R\&D) activities lead to internally developed products that are then distributed by the firm (Chesbrough, 2006). Maybe is useful to report the synthetic definition made by Chesbrough himself: "Open Innovation is the use of purposive inflows and outflows of knowledge to accelerate internal innovation, and expand the markets for external use of innovation, respectively". So, the Open Innovation paradigm treats R\&D as an open system. It assumes that useful knowledge is widely distributed, and that even the most capable R\&D organization must identify, connect to, and leverage external knowledge sources as a core process in innovation. A similar model generates flux of information and ideas exchange adaptable to the contemporary socio-economic models, and a reduction of the transition times between the material/product ideation and its effective commercialization.

Indeed, university research centers could stimulate SMEs and national economic development, adopting this model, which fosters the passage from a traditional model to more open one made of research and innovation development based on the integration of enterprises, consultants and different types of internal and external resources whit which it could be possible to cooperate.

So, MADEC research group dedicated time to open investigation methods and innovation through materials. In the spirit of the Open Innovation we worked to establish an open process for exploring and sharing knowledge, techniques and applications related to materials science, in order to encourage discourse and experimentation with the broadest range of materials.

The Open Innovation paradigm is sometimes confuted with Open Source methodologies; there are some concepts that are shared between the two, such as the idea of greater external sources of information to create value. More over, we strongly believe that opened and shared knowledge is the only way that will enable us to pin ourselves toward the future. In this direction MADEC's website is intended as a platform

\footnotetext{
${ }^{40}$ The work team coordinated by Marinella Ferrara and composed by Giampiero Bosoni, full professor of Interior Design and design historian; Giulio Ceppi, senior researcher of Industrial Design and architect, who cooperate in Domus Accademy with Ezio Manzini and Antonio Petrillo on the issue of materials identity; Andrea Ratti, associate professor of Industrial Design, designer in the nautical sector and expert on composites materials based on fibers; Chiara Lecce, $\mathrm{PhD}$ in Interior Architecture and Exhibition Design; Sebastiano Ercoli, PhD student and Naike Cogliati a young designer.
} 
to share knowledge, resources and discoveries, as well as document experiments and processes, which aims are:

- Collect different resources (news, techniques, theory, artworks, videos, etc.) and share them via links and blog posts;

- Create a repository of relevant materials, papers, tools and techniques;

- Document experiments, and share them via tutorials (video).

\section{Building the Design-driven Material Innovation Methodology}

Within the MADEC research program, one critical point has been to build a specific methodology able to integrate the tailor-made materials design process in the design research process, in order to create new scenarios of design concepts in which materials and products are conceived at the same time in relation to the specific contests of development

So, the "Design-driven Material Innovation Methodology" arose to enhance new products innovation and suggesting a method able to manage the design process in its whole complexity: form the material to the product and back including the commercialization models. Sometimes a specific material could be a starting point of the process, but not only. What the method really tries to do is to let designers, enterprises and innovators understand how to use technologies (and advanced materials) contextualizing them within a wider socio-cultural scenario.

As previously outlined, the methodology is part of an Open Innovation strategic learning context. This includes single innovators and start-up communities, business plan competitions, spin-off, research centers and universities, as receivers as well as contents developers, collaborating to the integration of different competencies, languages and founds supply.

The premise of this paper explains how the role of design is thus to look more comprehensively at materials, to respect the technical insight for considering sensory, emotional and symbolic qualities and, from this, giving a message to the consumers: a meaning that increases the value of products in the market.

Furthermore creative communities, scientists and material industries are becoming deeply engaged in the creative challenge to achieve material functionality and meaning and when new materials, products and production processes are conceived together, the industrial take-up time as well as time to market is minimized. As shown in Fig. 1, an exchange of trust occurs between stakeholders in a competitive environment. (Caisse \& Montreuil 2014, p.10). 


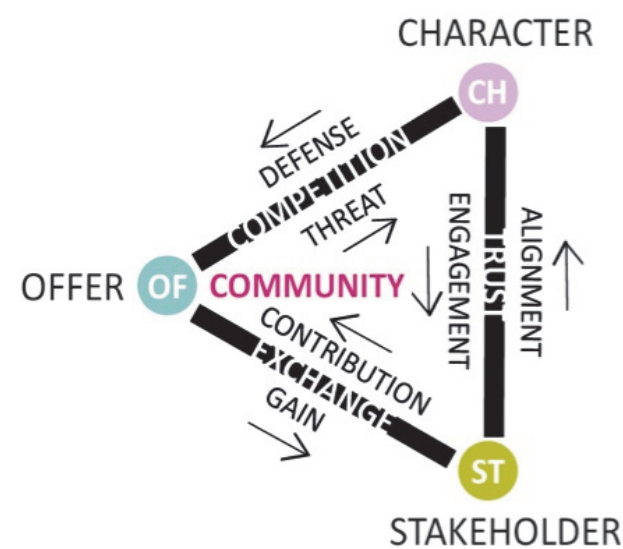

Fig 1. The community face of the "Offer-Creation-Character-Stakeholder" tetrahedron framework. Caisse \& Montreuil (2014).

\section{Method's referees}

\subsection{Integrative Thinking}

At the begging of this work it was essential to have a conscious knowledge of the actual panorama about generic creativity-driven methodologies.

An important referee to develop a correct methodology process was the publication titled Innovation Methods Mapping: de-mystifying 80+ years of innovation process design edited by GK VanPatter and Elizabeth Pastor with the Humantific $L a b^{41}$. Essentially the publication concerns an in deep analysis of a wide variety of innovation process models created since 1920s. In particular two main innovation process models have been compared: Applied Creativity (or Creative Problem Solving - CPS) and Design (or Design Thinking). The research found that there are three basic types of innovation process models: "Script models" that prescribe a series of detailed actions or behaviors, often with the caveat that nonlinearity is intended; "Zone models" that are more like scaffolds or frameworks inside which many action options are possible, often without any behavior prescribed; and "Script/Zone models" which combines the two. An other useful indication is that most CPS process models contain graphicallydepicted behaviors signals: diverge $<$, converge $>$ and deferral of judgment. Also "Open innovation", defined as multiple, internal and external humans engaging together to address challenges with open tools, has been part applied creativity (CPS) history since the 1940s. (Van Pattern \& Pastor, 2013)

The analysis ends with a list of ten "Common Innovation Method Design Missteps". Form that list we depict the most relevant for our intents: "Missing Meta Process", "Missing Separation of Content from Process", "Missing Behaviors", "Missing Visual SenseMaking", "Missing Cognitive Surfacing", "Missing Culture Connections". (Van Pattern \& Pastor, 2013)

The results of the entire work lead to the Integrative Thinking, which is the disciplined ability of recognizing, orchestrating and integrating the diverse brainpower of cross-disciplinary teams as they grapple with and navigate complex innovation challenges. Integrative Thinking is about recognizing and respecting the default thinking preferences of individuals regardless of discipline, and how those preferences map to innovation process. (Van Pattern, 2013)

41 A multi-disciplinary consultancy specializing in the creation of strategies, tools, and organizations that enhance adaptability and innovation based in New York. 


\subsection{Design-Driven Innovation}

A second step to define our methodology was looking outside of the design world. The management researches are now very interested in the successful practices of "design-driven innovation" in various industries. These design practices happens stressing design, instead of technology, in their innovation (Utterback et al., 2006). Design practices, focusing on new applications of materials as well new behaviors in society, are able to generate unexplored design solutions for new product concepts. To produce products which are design-driven innovation, companies need researchers who "envision and investigate new product meanings through a broader, in-depth exploration of the evolution of society, culture, and technology acting as interpreters who are able to envision how people could give meaning to things through intense involvement in the design discourse" (Verganti, 2009).

A research ${ }^{42}$ conducted in creative industries on the basis of Verganti's theory affirms: "To design new product meaning for new costumers, the company should sense the trend forecasting data which are collected with various methods by which various possible new meanings are produced. Then, the designer with his/her design paradigm helps the company do the sensemaking process in which the one of the possible new meanings is considered to be the best in anticipating a new trend is selected and defined. To translate the defined new meaning into a new product, the most suitable product language to express the defined new meaning -supported by selected appropriate technologies - is selected. The result will be used as specification to develop the new product." (Kembaren et al., 2014)

\subsection{Material Driven Design (MDD)}

Getting closer to the material design field, another relevant referee is looking at a newly founded research direction that scrutinizes materials' active role in shaping the users experiences with products (Ashby \& Johnson, 2009; Pedgley, 2009; Karana, Pedgley, \& Rognoli, 2014) and how to design for experiences (Wilkes et al., 2015).

In that direction, our attention focused on the Material Driven Design (MDD) methodology developed by a group of researchers, coordinated by Elvin Karana, from the Department of Design Engineering of the Delft University of Technology in collaboration with the Design Department of the Politecnico di Milano. The MMD method tries to give aesthetics character to DIY materials facilitate designing for material experiences. The design method starts focusing on a particular material. The design process individuate three main scenarios (Karana et al., 2015):

- Designing with a relatively well-known material in order to seek new application areas, evoke new meanings and to elicit unique user experiences;

- Designing with a relatively unknown material, accompanied by a fully developed sample in order to define application areas introducing unique user experiences, identities for materials, and new meanings;

- Designing with a material proposal with semi-developed or exploratory samples (e.g., food waste composites, living materials made of bacterial cells, 3D printed textiles, flexible OLEDs, etc.). Since the material is semi-developed its properties are to be further defined through the design process in relation to a selected application area. Furthermore, since the material is novel, the designer have to propose meaningful applications through which unique user experiences and meanings.

42 The contribution of the research by P. Kembaren et al. (2014), was to reveal that to deliver a new meaning successfully to the market, at least for the design-entrepreneur-led creative industry, there are ways other than the ones suggested by Verganti (2009). 
The method proposes four main steps: (1) Understanding the Material: Technical and Experiential Characterization, (2) Creating Materials Experience Vision, (3) Manifesting Materials Experience Patterns, (4) Designing Material/Product Concepts. As synthetized in Fig 2, the MDD process starts with a material (or a material proposal, based on the three possible scenarios previously listed), and ends with a product and/or further developed material. (Karana et al., 2015)

The method emphasizes the journey of a designer from tangible to abstract (i.e., from a material to a materials experience vision), and then from abstract back to tangible (i.e., from a materials experience vision to physically manifested, further developed materials/products). (Karana et al., 2015)

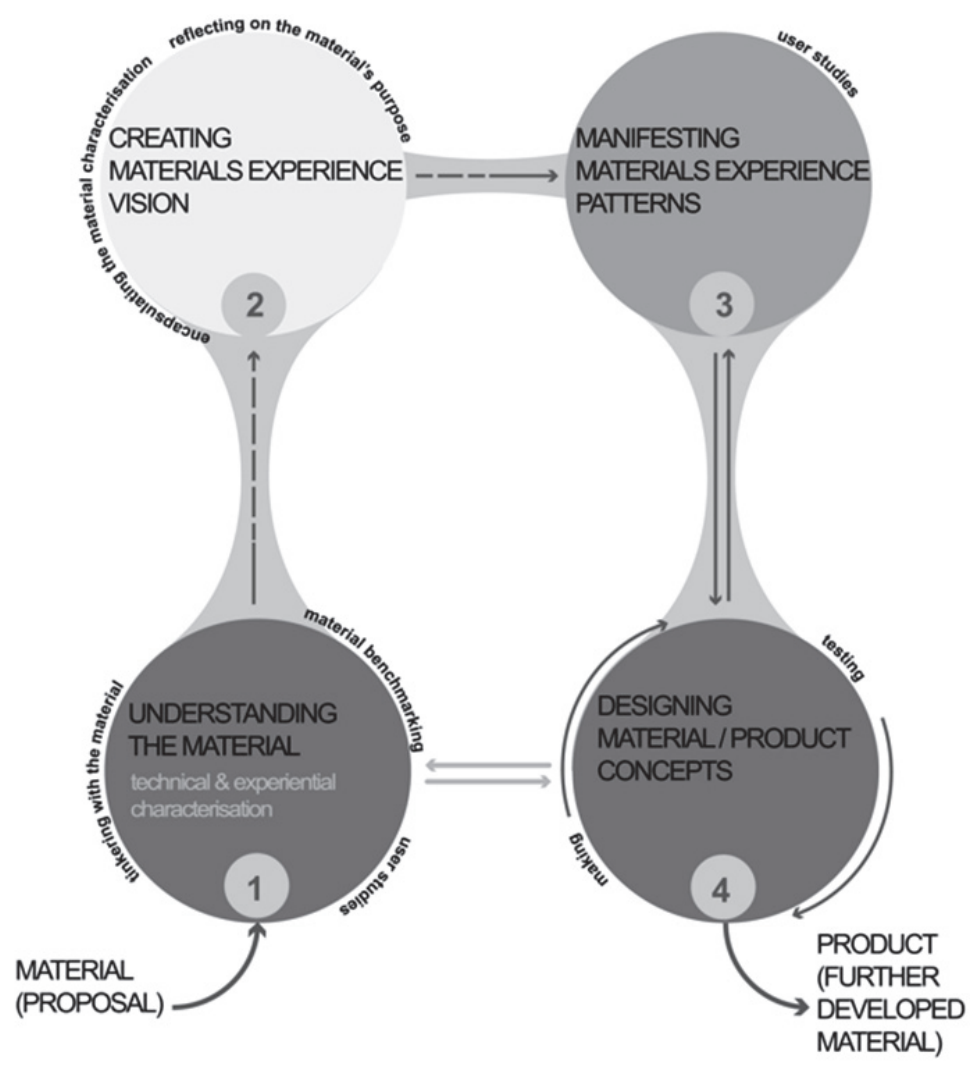

Fig 2. Material Driven Design (MDD) method. Karana et al. (2015).

\section{The Design-driven Material Innovation Methodology}

MADEC's "Design-driven Material Innovation Methodology" is the model that allows the development of one or more materials starting from scientific discoveries, material patents or production processes, in order to individuate applicative scenarios, to profile products lines, to develop specific products and to valorize them for the market launch.

Mixing and connecting all the referees previously displayed, MADEC's "Design-driven Material Innovation Methodology" (Fig 3) is based on a "Script/Zone" innovation process model. It consists in the reversal of the traditional problem solving approach to material design: material doesn't exist in its peculiarity before to be chosen, but is born out of the interpretation of the technical opportunity and the 
discussion with social necessities coming from a community of actors that acts in order to define and develop the innovation of a material and of a product simultaneously.

Another relevant character is the "meta-method" model, because to enable multiple participant orchestration is much more important than any technique, today most forms of cross-disciplinary work, not only require an externalized meta framework, but deep knowledge regarding how to apply it in various innovation contexts.

The material and its application are designed and realized starting from a "scenario" (sensemaking) that derives from a combined "sensing" process. The process converges to the Concept. The product concept itself defines the idea of the material, of its texture, performance and behaviors on the base of scientific advances and technological platforms (specifying). Then before to get the final product prototype a "design discourse" phase is necessary to complete the design-driven process. Once the product has been fixed, to deliver the new product with its defined new meaning into the markets, a storyline is carefully designed along with its product language to amplify and to relate the massage of the defined new meaning to the mind of the potential costumers (setting up). (Kembaren et al., 2014) Finally the product position inside the market diverges from different possible approaches connected to production processes (B2B or B2C).

Sometimes a specific material could be a starting point of the process, but not only, what the method really tries to do is to let designers or enterprises understand how to use technologies (and advanced materials) contextualizing them within a wider socio-cultural scenario.

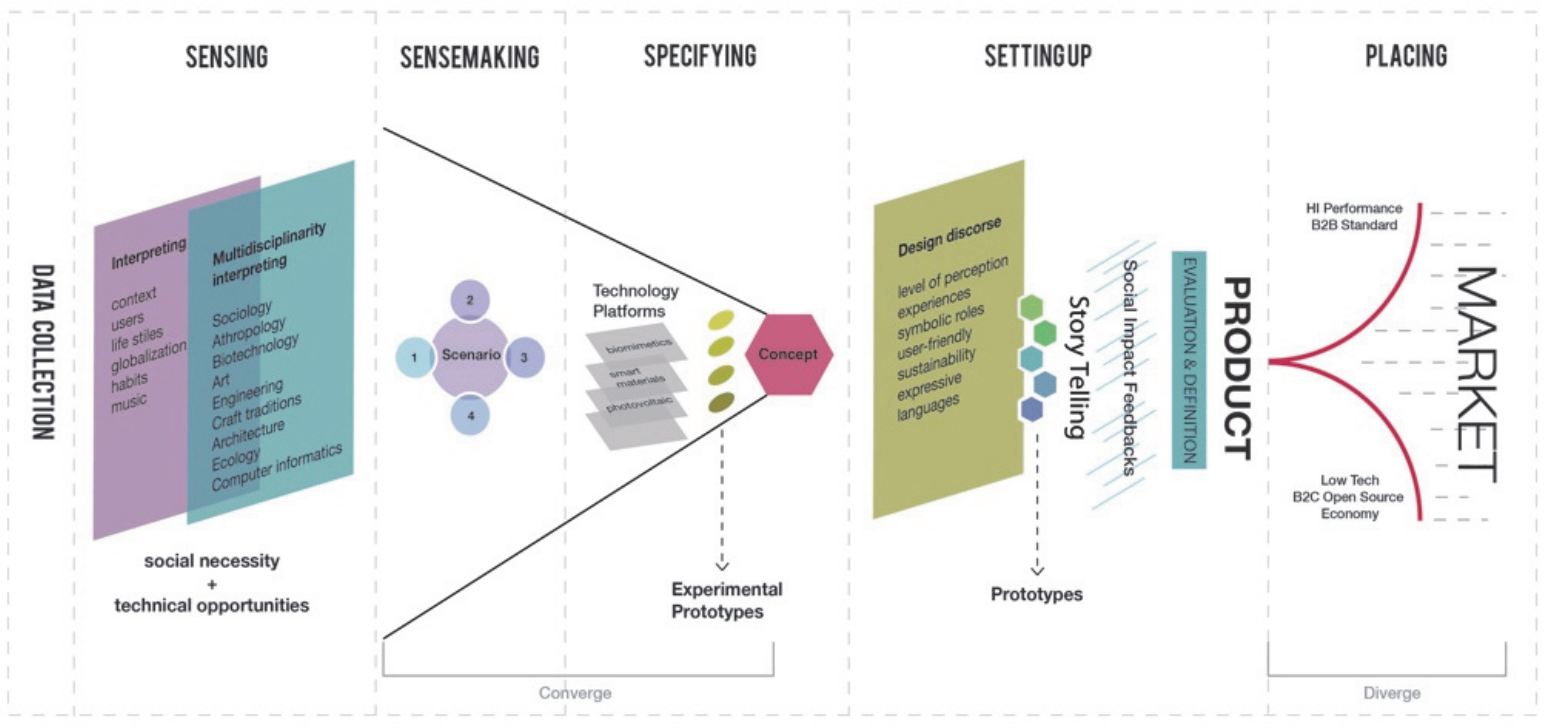

Fig 3. The Design-driven Material Innovation Methodology by MADEC.

\subsection{Data Collection}

The first step of DdMIM is the Data Collection, a "technical-cognitive" and "sensory-analytical" phase of the materials and its characteristics. 
This step includes three main actions (Fig 4):

- A deep analysis of the starting point material in order to acquire technical knowledge from scientists, technologist and material suppliers. This allows to acquire information about material potentialities, its opportunities to be molded and manipulated gaining sensorial characteristics defining the material for "what it is", "what it can do", "how it appears" and it behavior. It could be also useful to compare the material with similar o alternative ones to highlight differences and similitudes;

- Activities of benchmarking positioning the material in the contemporary materials scenario, among similar or different, without any preclusion to other production sectors, in order to find space of opportunity. This is a way of discovering which could be the best performance to achieve in application, use - whether in a particular sector, and in many other sectors. The information can be used to identify gaps of production in order to define potential spaces and new market;

- To "feel" the material trough manipulation: "hands on" approach and interpret the sensory potential of the material. About this last point, is important to stress on how physical encounters with materials or the aesthetic experiences that derive from "hands-on" (Nimkulrat, 2012) manipulation of materials can positively influence the creative process. The "learning by doing" often allows a deeper understanding of the relationship between materials, processes, and forms. For the first time in design history at the Bauhaus school were particular advocates of learning about/with materials. Around 1920, Johannes Itten formulated his "theory of contrasts". He asked students to explore sensorial contrasts relevant to materials, such as smooth-rough, softhard, and light-heavy. The theory of contrasts gave attention to the nature of materials, having the purpose of showing the essential and diverse characteristics of different matter. (Itten, 1975)

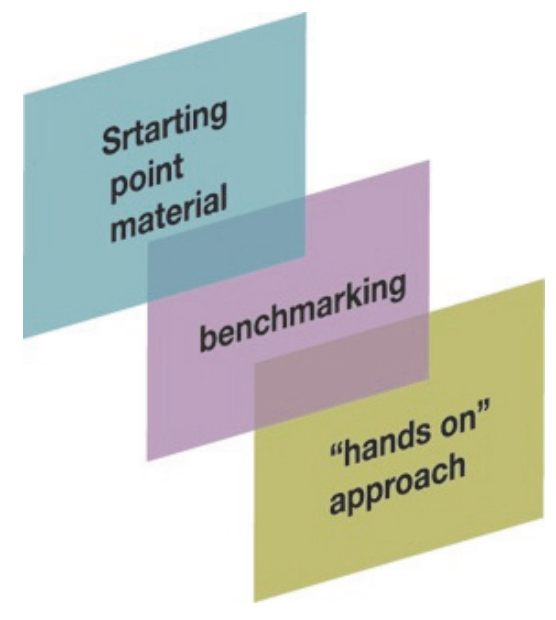

Fig 4. "Data Collection" phase from the D-DMIM method.

\subsection{Sensing}

The term sensing means: the perception that something has occurred or some state exists. During this phase it is very important to decide the context (geographical, cultural, social and economical) of the project to define cultural and behavioral characters and other emerging changings. Designers are able to 
scan lifestyles in a certain socio-cultural context. They recognize users tastes orientation and interpret them.

This phase must involve different actor (all the previously cited) and experts of various disciplines: humanistic (sociologists, anthropologists, psychologists, aesthetic experts) and technical and as well as users, in different section, in order to "extrapolate" helpful information and guidelines for the concept development.

Today's huge interest in multiple participant co-creation and collaboration, behaviors have become critically important, behavior synchronization is a key ingredient in any robust methodology-based, innovation-culture-building initiative. (Van Pattern \& Pastor, 2013)

Furthermore innovation design method is not just about making an abstract drawing of steps or assembling techniques: it is about to understand the role of innovation process in designing and deciding what kind of culture you want to create in your organization. This phase let define users' aptitudes, necessities and desires in relation to their physical, physiological, ideological and social well-being.

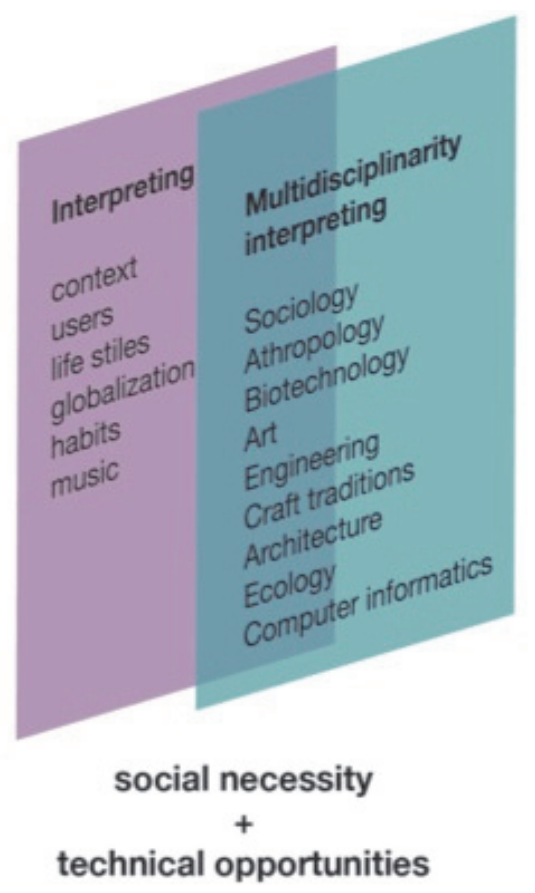

Fig 5. "Sensing" phase from the D-DMIM method.

\subsection{Sensemaking}

Using only words and numbers to solve problems and explain solutions, rather than words, numbers and pictures, significantly foreshortens the viewing lens and certainly the possible outcomes, today "sensemaking" is being recognized as a key 21 st century leadership navigation skill. (Van Pattern \& Pastor, 2013)

So, during the "sensemaking" phase designers develop ideas about what could or should be possible with the material, envisioning a concept, i.e. a "material vision" that defines the new meanings for the material anticipating new trends. Designers have to use imagination to innovate and open up different visions compared to the past defining specific "scenarios" where the general concept can be collocated. To help 
this activity is possible to individuate four "W" questions (Fig 6): What (describe), Why (explain), Will (predict) and What if (foresee).

\section{SENSEMAKING}

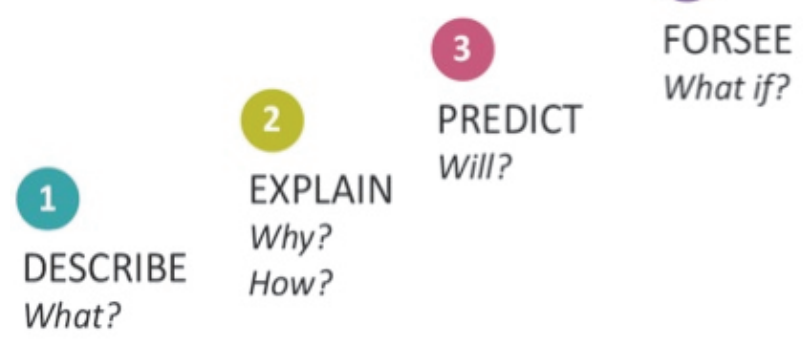

Fig 6. The four W scheme individuated by the "sensemaking” pahse.

To better understand the "sensemaking" phase we can choose a possible "scenario" and an applicable case study. Sustainability is becoming a social need and can represent an "ideo-pleasure" ${ }^{\text {"43 }}$ which means pleasures that are connected to people's values, and this reflection derives from the "sensing" phase. After that, since materials are at the core to the question of sustainability in terms of resources and energy, in an environmentally conscious society, the use of a product manufactured from bio-plastic fully recyclable and biodegradable, could create appreciation and user satisfaction.

This is the scenario from which the Kuskoa Bi chair project derives. Designed by the Alki workshop is the first chair made of a plant-based polymer, using oak from sustainably managed forests and upholstery made from $100 \%$ natural materials. If we read the premise presented by the creators of this project is quite evident the scenario where they collocate their product concept: "Set against the backdrop of the Pyrenees, nestling in a valley at the foot of the mountains is the village of Itsasu and the Alki workshop. Surrounded by nature, this is a unique environment in which it is a privilege to work and one which we strive to protect by seeking out new and integrated methods of production".

And the specific choice of that particular material derives also form a previous step of "data collection" because they have analyzed the material in its technical proprieties evidencing that similarly to synthetic polymer, it can be injected, extruded and thermoformed but it is made from plant-based renewable resources (beet, corn starch, sugarcane, etc.). The bio-based polymer is also fully recyclable and its organic properties mean that, when subjected to an industrial process, it is biodegradable. Moreover, another significant environmental aspect lies in its reduced carbon footprint as bioplastic production results in reduced greenhouse gas emissions.

\footnotetext{
${ }^{43}$ According to Lionel Tiger's pleasure model described in his book The Pursuit of Pleasure (1992), Patrick Jordan (2002) adapted it to products individuating four types of pleasure that can be considered when interacting with products: "physiopleasures"(sensorial pleasure), "socio-pleasures"(the pleasure that comes form social life), "psycho-pleasures"(cognitive loadmatching mental models) and "ideo-pleasure"(identity, intellectual).
} 

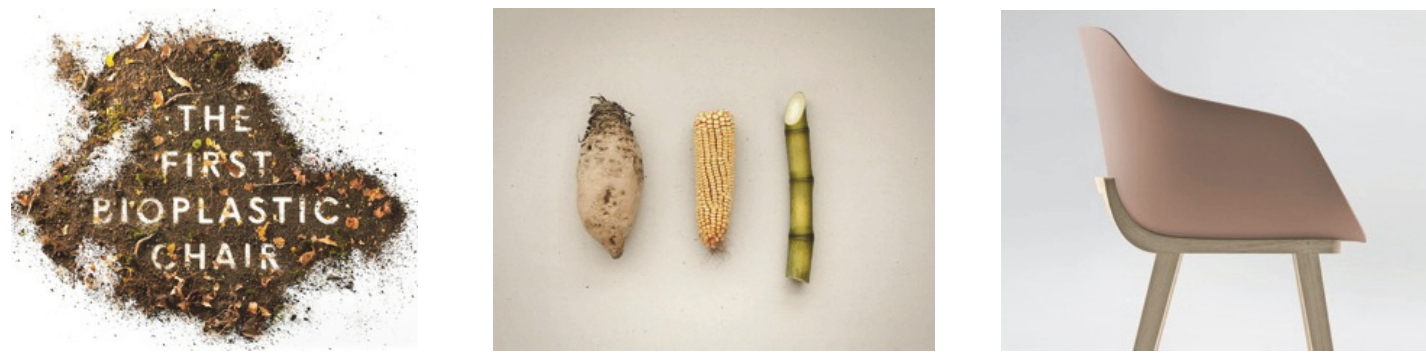

Fig. 7 The Kuskoa Bi chair by Alki workshop, (2014).

During the sensemaking phase designers develop ideas about what could or should be possible with the material, envisioning a concept, i.e. a "material vision" that defines the new meanings for the material anticipating new trends.

\subsection{Specifying}

In order to translate the defined new meaning into a new product, the most suitable product language is selected. The result will be used as specification to develop the first experimental prototype of new material product. This process converges to the Concept. The product concept itself defines the idea of the material, of its texture, performance and behaviors on the base of scientific advances and technological platforms (Fig. 8).

Another useful case study can be associated to this phase: the Wood-Skin ${ }^{\circledR}$ project. It was developed by a young Italian start-up composed by a team of four members combining ten years of knowledge, from university study to professional activity. The variety of skills and approach brought by each member of the team made possible to transform pure creativity into practical applications. The vocation and area of knowledge of each team member has merged seamlessly to produce a well-rounded group, each complimenting the others. Their concept derives form a "specifying" phase that combine together different characteristics starting form a traditional material - wood - revolutionizing it through transforming it in a composite material and a new "one step fabrication process". The wood becomes tissue-alike and able to be shaped in many forms yet retaining their structural and aesthetic value intact, simultaneously. More over Wood-skin, combining the rigidity of traditional materials with the flexibility of textiles, it allows countless applications both to entirely customizable architectural and design elements. 


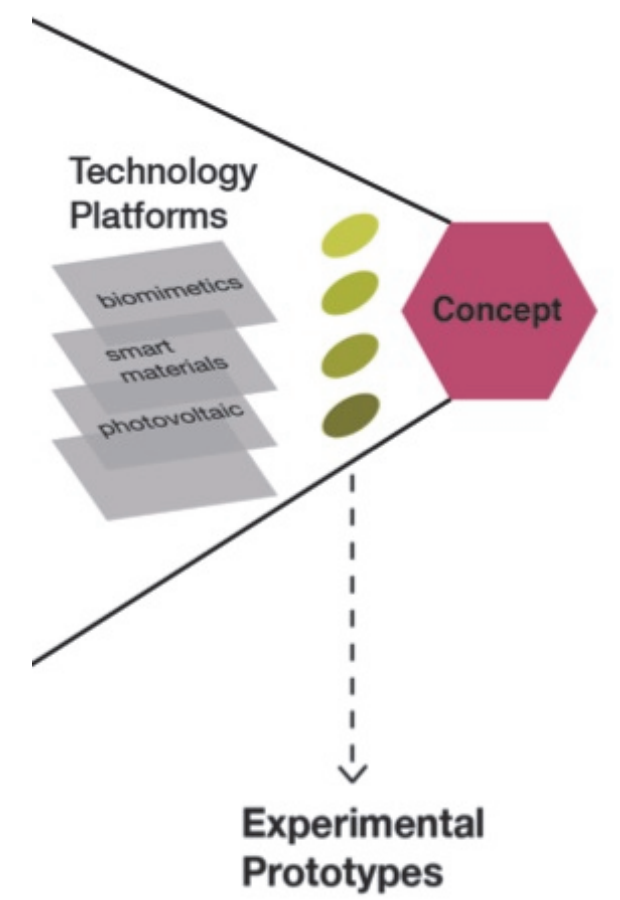

Fig. 8 "Specifying" phase from the D-DMIM method.

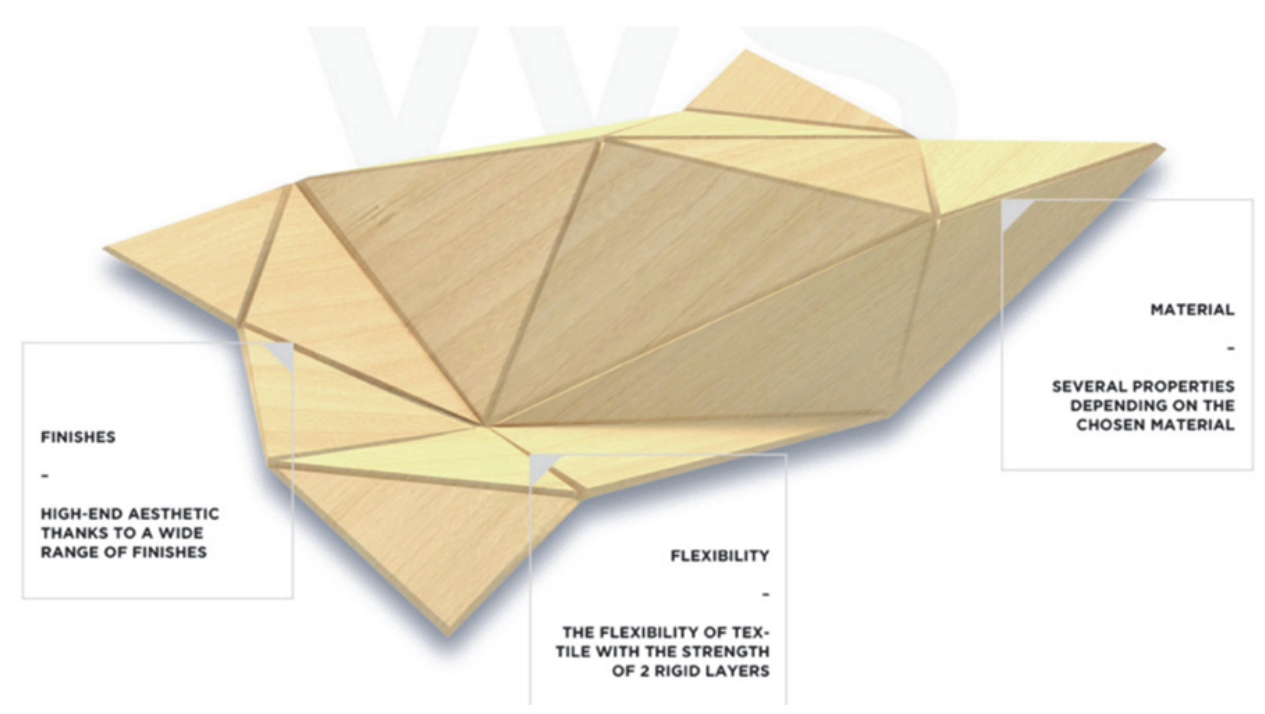

Fig 8. Wood-Skin ${ }^{\circledR}$ 's concept proprieties.

\subsection{Setting up}

When the design discourse on the material qualities is defined it can start a development stage of the material applications for products design. But, a really strategic step of this phase is the "storytelling". In fact, to deliver the new product with its defined new meaning into the markets, a storytelling has to be carefully designed along with its product language to amplify and to relate the message of the defined new meaning to the mind of the potential costumers.

The role of design is thus to look more comprehensively at the new product, to respect the technical insight for considering sensory, emotional and symbolic qualities and, from this, giving a message to the 
consumers: a meaning that increases the value of products in the market. Also the "User Acceptance" of a material/product depends on the correspondence of the experiences with the society needs or cultural trends, as well on the ability to communicate the meaning of material/product innovation. Visual communication skills are fundamental in this process: the message should be pleasant and easily understood by consumers to let the new product be accepted, desired and chosen by the consumers.

Finally, organizing a material experience session of potential users the innovation social impact could be evaluate before to place the product into the market.

There are several case studies of successful storytelling applications. One is related to material rather than a specific product. Litracon is translucent concrete invented by the Hungarian architect Áron Losonczi, who tackled the issue of glass in architecture, learned about optical fibers and made contact with Schott, a world's leading manufacturer of optical fibers, for his experiment with glass fibers cast in concrete (20012003). Litracon Classic ${ }^{\circledR}$ was listed among the most important inventions of the 2004 by TIME magazine but to get people confident with this new material/product the company understood that it was necessary to "tell" something more about it.

"You Are Energy" is the name of the installation designed by Gagarin Ltd. with Tvíhorf Architects to catch people's attention. It consisted of a big, interactive concrete wall made of Litracon Classic ${ }^{\mathbb{B}}$ blocks which illuminates from within when a force is applied to it. Visitors were invited to test their strength and met the challenge of inducing an explosion.

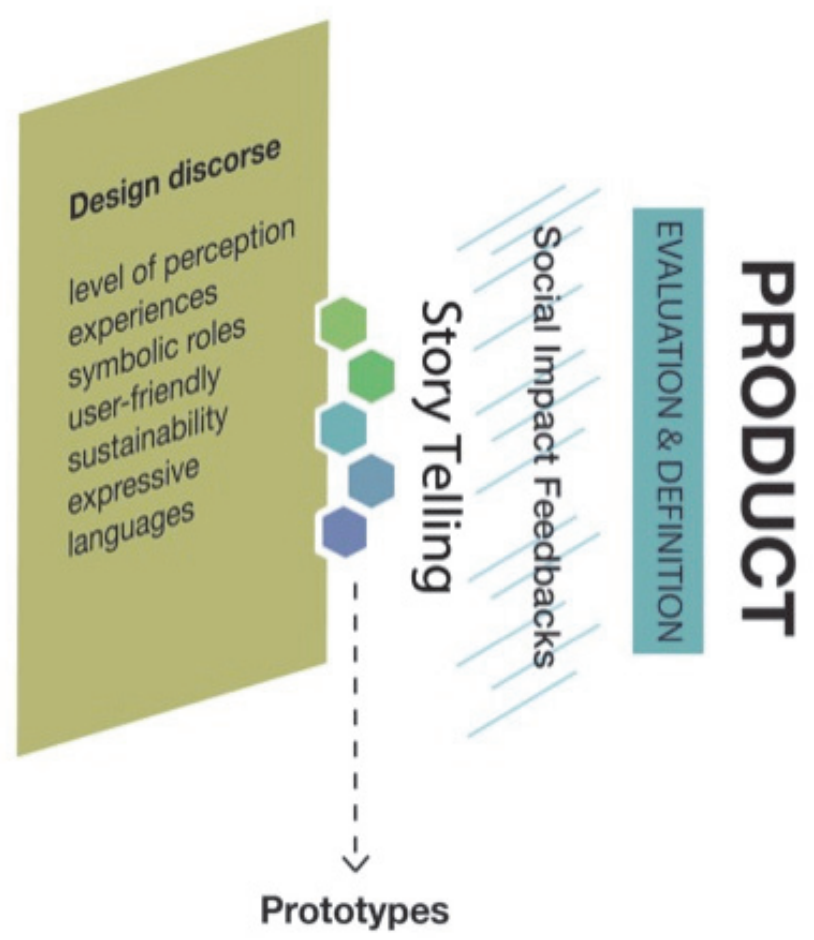

Fig. 9 "Setting up" phase from the D-DMIM method. 

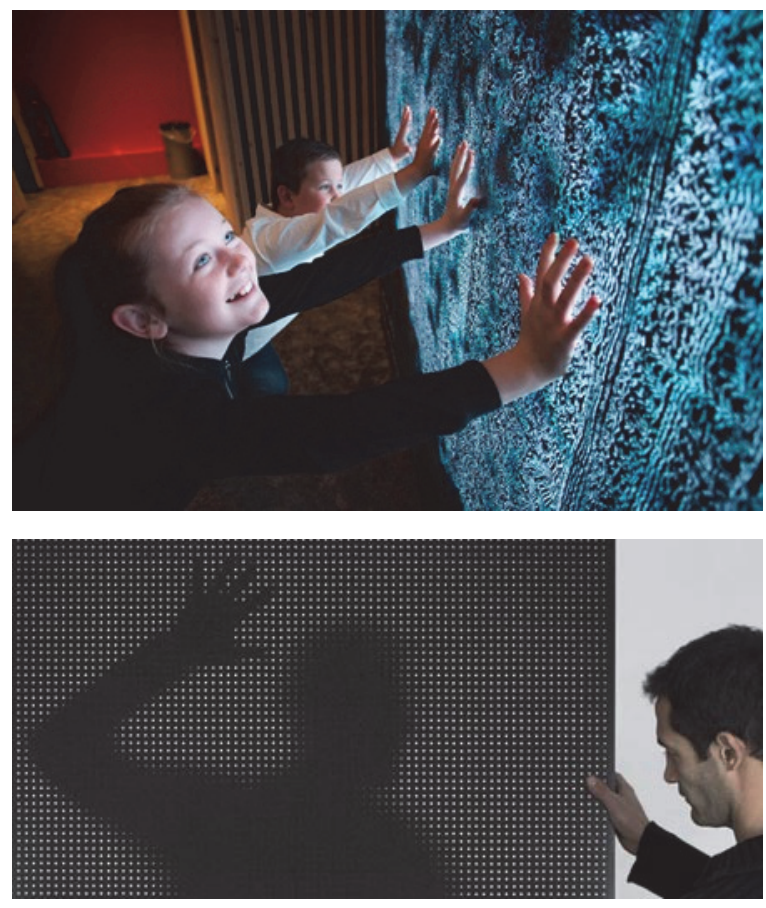

Fig 10. "You Are Energy" installation made of Litracon Classic ${ }^{\circledR}$ blocks at "Powering the Future" exhibition in Iceland, (2015).

\subsection{Placing}

Finally, the design can define how to place the material/product on the market. In this phase it is suggested to consider at the same time various distribution channels to the ultimate purchaser or end-user.

Today it is important assure that the product position inside the market diverges from different possible approaches connected to production processes - Business to Business (B2B) or Business to Consumer (B2C). But getting closer to this phase becomes competence of business experts rather than designers. The design contribute in this stage can be the implementation of the visual communication of the product. 


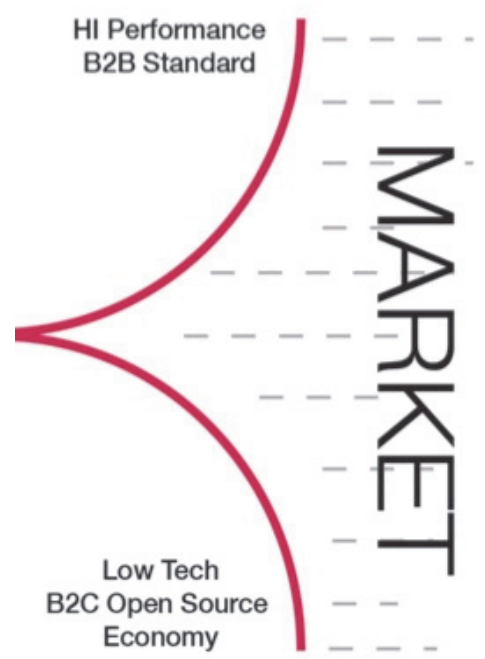

Fig 9. "Placing" the final phase of the D-DMIM method.

\section{Conclusions}

Getting to the conclusion of this paper it is possible to summarize the principal DdMIM characteristics:

- It is based on material design and product design integration, trough a deeper understanding of material qualities;

- It focuses on new values and meanings, centered on human pleasure and consumers needs;

- It enables the collaboration between researchers, designers, and companies through an open innovation processes;

- It integrates multi-skills in a cross-fertilization process;

- $\quad$ It is useful for envisioning and developing new product concepts.

Moreover, a material innovation success depends on two other relevant design outcomes: distinctiveness and user acceptance. In a world were the number of products becomes greater and greater, material can make the difference to the competitors, for distinctiveness of your products in the market. An finally the material innovation value and message should be pleasant and easily understood by consumers, that means to increase the ability to communicate the material innovation (user acceptance).

Actually the DdMIM is part of the Design for Enterprises, the winner project of the Tender Capabilities for Design-Driven Innovation in European SMEs funded by EASME (Executive Agency for SMEsEuropean Commission). D4E is a consortium established between MIP- Politecnico di Milano, D'Appolonia and ADIPER and will be a three years long European training program in order to help SMEs to manage a design process for product and services innovation where different actors like materials scientists, suppliers, creative communities and consumers are getting engaged. 


\section{References}

ADAMOVIC, N. (2014). "Best Practices for Collaboration between Creative and Material Communities" in LET'S Leading Enabling Technologies for Societal Challenges - symposium, Bologna (Italy).

ASHBY, M. (2009). Materials and Design. Butterworth-Heinemann.

BOSONI, G. \& FERRARA, M. (2014). Italian Material Design: learning from history. Ais/Design Storia e Ricerche, 4. http://www.aisdesign.org/aisd/italian-material-design-imparando-dalla-storia $>$ [Consulted: $10^{\text {th }}$ of May 2016].

CAISSE, S. \& MONTREUIL, B. (2014). Polar Business Design. SAGE Open January-March 2014.

$<$ http://sgo.sagepub.com/content/4/1/2158244014522632.full.pdf + html $>$ [Consulted: 4th of November 2015].

CHESBROUGH, H. (2006). Open Innovation: Researching a New Paradigm, Oxford University Press.

FERRARA, M. \& LECCE, C. (2015). "MADEC. Material Design Culture" in E. Duarte, C. Duarte, F. Carvalho Rodrigues (Eds.), Senses \& Sensibility '15: Design as a Trade, proceedings of the UNIDCOM/IADE 8th International Conference, pp. 490-497. Lisbon: IADE-Creative University.

JORDAN, P. W. (2002). Designing Pleasurable Products: An Introduction to the New Human Factors. CRC Press.

KARANA, E., BARATI, B., ROGNOLI, V., \& ZEEUW VAN DER LAAN, A. (2015). "Material Driven Design (MDD): A Method to Design for Material Experiences" in International Journal of Design 9 (2).

KARANA, E., PEDGLEY, O., \& ROGNOLI, V. (2014). Materials experience: Fundamentals of materials and design. Oxford, UK: Butterworth-Heinemann.

KEMBAREN, P., SIMATUPANG, T. M., LARSO, D., WIYANCOKO, D. (2014). "Design Driven Innovation Practices in Design-preneur led Creative Industry" in Journal of Technology Management \& Innovation (9) 3, Santiago.

LECCE, C. (2015). "MADEC: Exploring new methodologies to transfer material knowledge into design disciplines" in Bang, A. L., Buur, J., Alma, I., Nimkulrat, N. (Eds.), Tangible Means. Experiential Knowledge Through Materials, EKSIG, p. 278-297. Denmark: Design School Kolding.

NIMKULRAT, N. (2012). "Hands-on intellect: Integrating craft practice into design research" in International Journal of Design, 6(3), p.1-14.

PEDGLEY, O. (2009). "Influence of stakeholders on industrial design materials and manufacturing selection" in International Journal of Design, 3(1), 1-15.

UTTERBACK, J. M., VEDIN, B., ALVAREZ, E., EKMAN, WALSH SANDERSON, S., TETHER, B., VERGANTI, R. (2006). Design-inspired Innovation. World Scientific Publishing Company.

VAN KESTEREN, I. (2008). Selecting materials in product design (Doctoral dissertation). Delft University of Technology, Delft, The Netherlands.

VANPATTERN, GK. \& PASTOR, E. (2013). Innovation Methods Mapping: de-mystifying 80+ years of innovation process design. OPEN Innovation Consortium.

VANPATTER, GK. (2013). Humantific Innovation Methods Mapping. Systemic Design Conference, Oslo School of Architecture \& Design, Oslo Norway.

VERGANTI, R. (2009). Design Driven Innovation: Changing the Rules of Competition by Radically Innovating What Things Mean. Harvard Business Press.

WILKES, S., WONGSRIRUKSA, S., HOWES, P., GAMESTER, R., WITCHEL, H., CONREEN, M., MIODOWNIK, M. (January 2016). "Design tools for interdisciplinary translation of material experiences" in Materials \& Design, Vol. 90, p. 1228-1237.

ZUO, H. (2010). "The selection of materials to match human sensory adaptation and aesthetic expectation in industrial design" in METU Journal of the Faculty of Architecture, 27(2), p. 301-319. 